\title{
Senior High School Students' Ability in Posing System of Linear Equations in Two Variables Problems
}

\author{
Yemima Indah Rachmawati ${ }^{1)}$, Eko Sugandi ${ }^{1)}$, Lydia Lia Prayitno ${ }^{1)}$ \\ ${ }^{1)}$ Department of Mathematics Education, Universitas PGRI Adi Buana Surabaya \\ Corresponding Author:yemimaindabr@gmail.com
}

\begin{abstract}
Problem posing is a learning approach that trains students to be able to process and communicate mathematical problems based on information obtained. This study aims to describe the ability of high school students to pose problems on the topic of the system of linear equations in two variables (SLETV). This study used a quantitative descriptive study involving 60 high school students in the East Surabaya area. The results showed that students were able to submit 60 problems where consists of 54 problems can be categorized and 6 problems could not be categorized. Based on the semantic structure of mathematics, there were about 17 students $(31,48 \%)$ which is able to pose problems using 1 relationship. Moreover, as many as 13 students (24,07\%) were able to pose problems using 2relationships. Besides that, 13 students (24,07\%) were able to propose problems using 3-relationships while the remaining 11 students (20,37\%) able to pose problems using 4-relationships. Based on the language structure (syntax), about 23 students (42,59\%) were able to pose problems using assignment propositions. Furthermore, as many as 17 students (31,48\%) were able to pose SLETV problems using relationship propositions while the remaining 14 students (25,93\%) were able to pose a problem using a presupposition proposition. Thus, it can be concluded that based semantic structure, students more easily posed problems one relationship. But, based on language structure (syntax), most students are able to pose problems using the proposition of proposition.
\end{abstract}

Keywords: problem-posing, syntax, semantics, students ability

Received: $3^{\text {rd }}$ October 2018, Revised: $21^{\text {st }}$ January 2019, Accepted: $21^{\text {st }}$ January 2019

\section{Introduction}

Mathematics is one of the subjects that has an important role in our life as Berch and Mazzocco (2007) stated that learning math has an important thing in daily life. Mathematics is needed by students to learn and understand other subjects, such as sciences, economics, and others. However, today, the students are less interested in mathematics because it is considered a difficult subject to understand.

Furthermore, Gardiner and Borovik (2007) stated that everyone has mathematical abilities possessed, but some children may have more abilities than the others. Each student has mathematical abilities, but some students have abilities that go beyond other students. Basically, every student has mathematical abilities that depend on the attitude of the student. Differences in the students' mathematical abilities are related to knowledge, experience, and skills that have been mastered by students. The differences in 
mathematical abilities will affect all actions both in terms of understanding questions, interpreting questions, and solving problems. It is necessary to optimize the role of the teacher in the learning process to explore those mathematical abilities. The teacher must be able to be a good and correct facilitator so that he is expected to know the students' abilities and potential.

The ability of students to pose the problems is one of the potential possessed by students that need to be studied and developed. Propose of the problems is a learning approach that trains students to be able to process and communicate mathematical problems based on information obtained to be a new question or problem. Posing a problem can train students' thinking skills because the students would be thinking about whether the problem proposed can be resolved or not. They also would be analyzing whether the problem raised is related to the existing material, can be understood by other people, and how the answer to the problem proposed. This is in line with Brown and Walter (1990) stated that autonomous thinking process students can develop through problem-posing. In addition, Cai, et al., (2015) stated that problem posing gives students some benefits as it helps students to increase their mathematical ability such as conceptual understanding, problem solving and creativity.

In addition, Silver, E. A \& Cai (1996)argue that posing the problem is interesting for several reasons, i.e. the relationship between creativity and extraordinary mathematical skills, developing students' ability to solve problems, opening a window of students' understanding of mathematics, fostering students' interest in mathematics, and help students become independent individuals. Furthermore, the results of Silver and Cai (1996) inform that students with high problem-solving skills have the ability to pose good problems, both in terms of response quality and the quantity of semantic and syntactic relationships. This is reinforced by Tuğrul (2010)which explains the existence of a significant relationship between the skill of posing problems and solving problems. Moreover, there are parallels between the number of problems raised and success in solving problems.

Silver and Cai (1996) provide the term problem posing applied to three different forms of mathematical cognitive activity, namely: 1) pre-solution posing, that is when students pose the problems based on the problems that have not been resolved before, 2) within-solution posing, which is a student formulates or remakes the problem as it is being resolved, and 3) post-solution posing, which is a student modifies the purpose or condition of the problem that has been resolved to create a new problem that is similar. Furthermore, Silver and Cai (1996) divided the posing of the problem into three responses, namely:

1. Mathematical questions, namely questions that contain mathematical problems and which are related to the information provided. This math question is also divided into two, namely:

a. Solvable math questions, that is the questions made by students contain enough information from the information that is there to be completed. Mathematical questions that can be solved are divided into two, namely mathematical questions that contain new information and mathematical questions that do not contain new information.

b. Non-solvable math questions, that is the questions made by students have a purpose that is not in accordance with the information provided.

2. Non-mathematical questions, namely questions that do not contain mathematical problems and have no connection with the information provided.

3. The statement, which is a form of problem that does not contain question sentences that lead to mathematical questions and non-mathematical questions. 
The classification of the complexity of the questions made by students according to Silver and Cai (1996) is as follows.

1. Complexity related to the structure of language (syntax)

The complexity associated with the structure of language can be seen based on the form of propositions contained in the problems made by students. The three propositions in mathematical story problems are as follows.

a. Assignment proposition, which is a question that contains a task to be done.

b. Relational proposition), which is a question that contains a task to compare.

c. Conditional proposition), which is questions that use additional information.

To indicate the syntax, Silver and Cai (1996) stated that the presence of conditional or relational propositions is an indicator of problem complexities. This means that the presence of presuppositions and relationship propositions can be used as an indication of the complexity of the problem posed by the student.

2. Complexity related to mathematical structures (semantics)

Silver and Cai (1996) use problem classification schemes to group questions made by students in terms of their semantic structure, namely, change, group, compare, restate, and vary. Change, that is the problem proposed uses different data with the information provided. Group, that is the problem proposed uses some information contained in the information provided or is able to combine several points of questions in a question. Compare, that is the problem proposed contains a comparison element with the initial information. Restate, which is the problem presented only contains information already in the information provided and the answer can be found directly in that information. Vary, that is the problem proposed uses some information contained in the information provided and also contains new information that is different from the initial information that has been given. Silver and Cai (1996) stated that the problem posed is better to contain many semantic relationships so that the problem becomes more complex. This means that problems involving many semantic relationships can be said to be complex rather than problems that involve only a few semantic relationships.

Many researchers have been investigated students ability in posing problems in various topics. Based on this description, the researcher was interested in conducting a similar study in which the research carried out was titled the Ability of High School Students to pose the SLETV Problems. The research was conducted on 60 high school students in the East Surabaya area, namely by giving a test in the form of a problem pose test sheet. In addition, in this study, one form of cognitive activity is used pre-solution posing. This is because to know the ability to understand concepts about the material that has been obtained and mastered by students after following the learning process. Whereas, one form of posing the problem used in this study is a mathematical question that can be solved. This is due to the understanding of concepts, thinking skills, and reasoning abilities and connecting the interrelationships between mathematical concepts in posing problems.

One of the subjects in mathematics related to students' ability to pose problems is SLETV which is a collection of linear equations that have the same solution for all equations consisting of two variables. Furthermore, through this SLETV material the researcher can find out how far the student's ability to raise problems is based on the information he has mastered.

\section{Research Methods}

This research is quantitative descriptive research. The data sources in this study were sixty of $10^{\text {th }}$ grade students in the East Surabaya in the 2017/2018 academic year. The instrument used in this study was a test. In this case, a test was used to propose a 
SLETV problem. Data collection in this study was conducted by giving a test in the form of a problem pose task sheet (LTPM - Lembar Tes Pengajuan Masalah). This LTPM is given to students and is done individually to know the students' ability to pose problems, especially in the topic of SLETV.

The task of submitting the problem is used one cognitive form, namely pre-solution posing. In this case, students were given information in the form of statements relating to SLETV material. Through the information available, it is expected that students are able to pose the problem as much as possible and then complete it within 60 minutes. Figure 1 showed the LTPM.

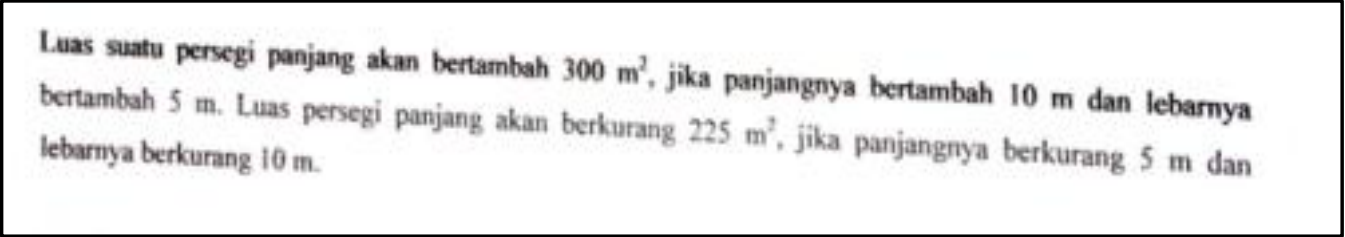

Figure 1. The problem posing sheet

Analysis of the data used in this study in accordance with the data analysis used by Dwianto \& Siswono (2016) as follows.

1. Problem classification

Data results were analyzed by classifying the problems that have been submitted by students. Classification is done by sorting out the problems posed by students in the form of mathematical questions, non-mathematical questions, and statements. If the problem posed by students is in the form of statements, non-mathematical questions, mathematical questions that cannot be solved, and mathematical questions that have the wrong answers then in this study "not categorized". In this study, mathematical questions that can be solved will be categorized.

2. Analysis based on mathematical structure (Semantic)

Mathematical questions that can be solved were analyzed based on the complexity associated with the (semantic) mathematical structure. This is based on five semantic relationships of the problems posed by students. The problem is analyzed for the number of semantic relationships that are used whether the proposed problem uses 1-relationship, 2-relationship, 3-relationship, and 4-relationship. As for the relationship in question is whether the problem posed by students includes changing, classifying, comparing, restate, and vary.

3. Analysis based on language structure (Syntax)

Mathematical questions that can be solved were analyzed based on the complexity associated with the structure of language (syntax). This is done by looking at the propositions used by students in raising problems. The propositions include assignment propositions, relationship propositions, and supposition propositions.

\section{Results and Discussion}

The Problem Pose Test Sheet (LTPM) provided contains information relating to SLETV material. The results of the description of the problem proposed by students are as follows.

Table 1. Proposed Classification Results

\begin{tabular}{ccc}
\hline $\begin{array}{c}\text { The Number } \\
\text { of Problems }\end{array}$ & Categorized & Uncategorized \\
\hline 60 & 54 & 6 \\
\hline
\end{tabular}


Based on Table 1, it can be seen that approximately $90 \%$ of students able to pose the categorized mathematical problem which is the mathematical question that can be solved. While the remains $(10 \%)$ pose the uncategorized problem. Furthermore, All categorized problem will be analyzed based on complexity related to the mathematical structure (semantics). The results of the analysis based on complexity related to semantics are as follows.

Table 2. Results of Semantics Analysis

\begin{tabular}{ccccc}
\hline The Number & \multicolumn{4}{c}{ Semantic } \\
\cline { 2 - 5 } of Problems & $1-\mathrm{H}$ & $2-\mathrm{H}$ & $3-\mathrm{H}$ & $4-\mathrm{H}$ \\
\hline 54 & 17 & 13 & 13 & 11 \\
& 31,49 & 24,07 & 24,07 & 20,37 \\
\hline
\end{tabular}

Note:

1-H: 1 semantic relationship

2-H: 2 semantic relationship

3-H: 3 semantic relationship

4-H: 4 semantic relationship

Based on Table 2, more than one-third of students were only able to pose problems using 1-relationship. While the students who were able to pose problems using two or three relationships are as many as $24.07 \%$. Moreover, the students who were able to pose a problem by using four relationships has the lowest percentage that is equal to $20,37 \%$. Therefore, it can be concluded that the students more easily posed problems that involve one relationship. So, they have to reread the relational sentence to determine the relationship (Pape, 2004) before posed the problems.

The student posed problems using 1-relationship

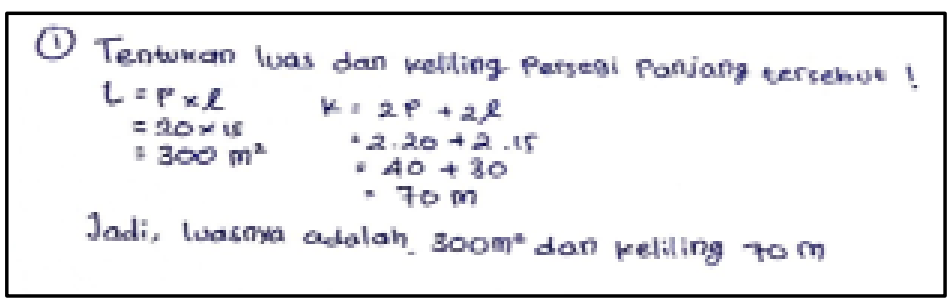

Figure 2. The problem using 1-relationship

Based on Figure 2, the problems posed by the student can be categorized using 1relationship, namely grouping. In this problem, the student was able to combine several questions into a question, that is calculating the area and circumference of the rectangle.

The student posed a problem using 2-relationship

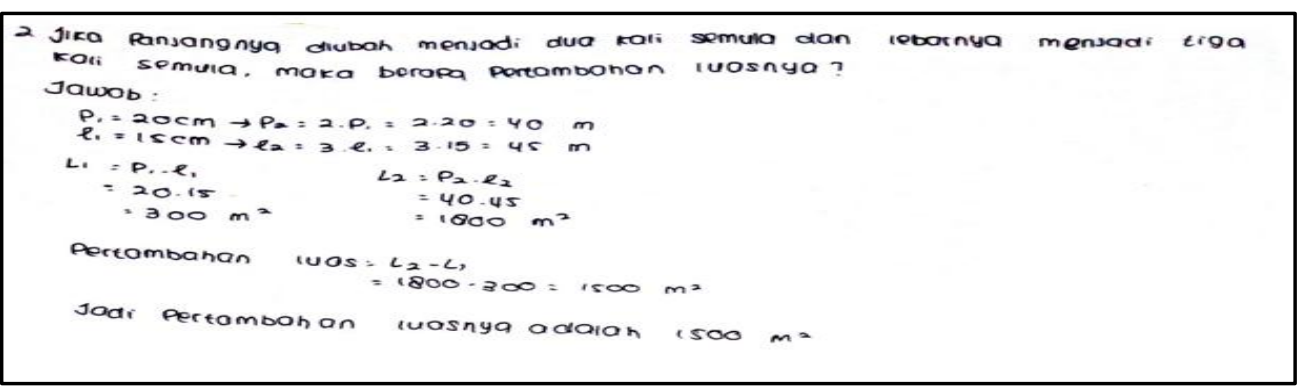

Figure 3. The Problem using 2-relationship 
Based on Figure 3, the problems posed by students can be categorized as restating and changing. In this problem, the student used existing data in the form of the length and width of the original size then change the length to twice the original size and width to three times the original.

The student posed a problem using 3-relationship

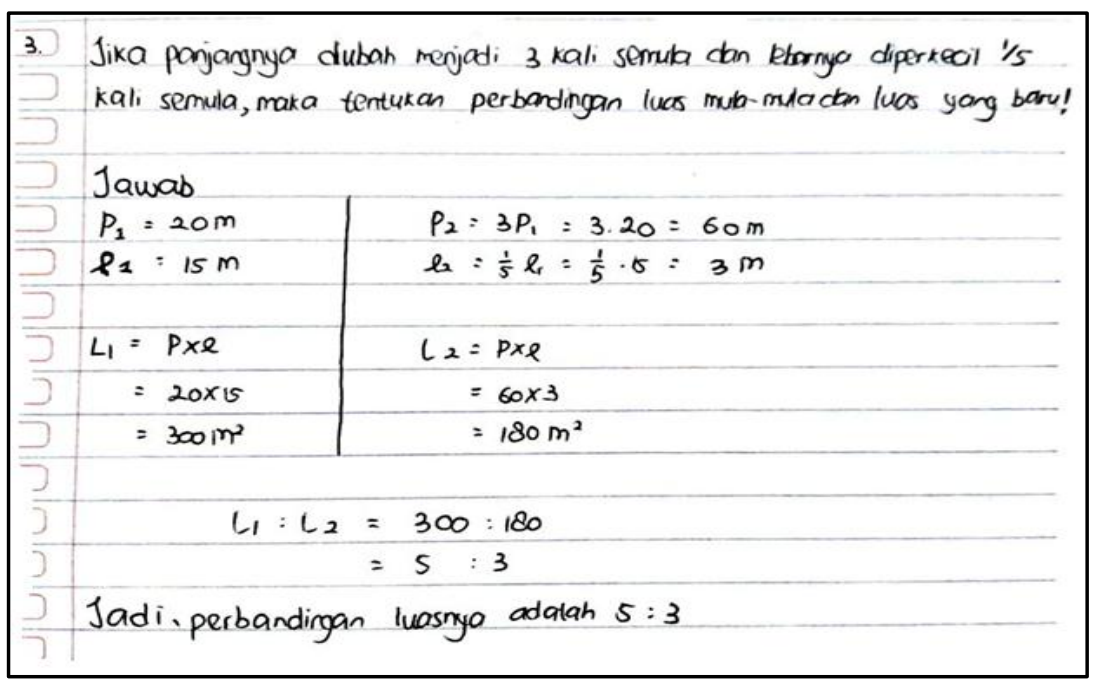

Figure 4. The problem using 3-relationships

Based on Figure 4, the problems posed by students can be categorized as restating, changing and comparing. The student used the existing data in the form of the size of the original length and width then change the length to three times the original size and width to one fifth the original. Next, students also compare the area based on their respective sizes.

The student posed a problem using 4-relationship

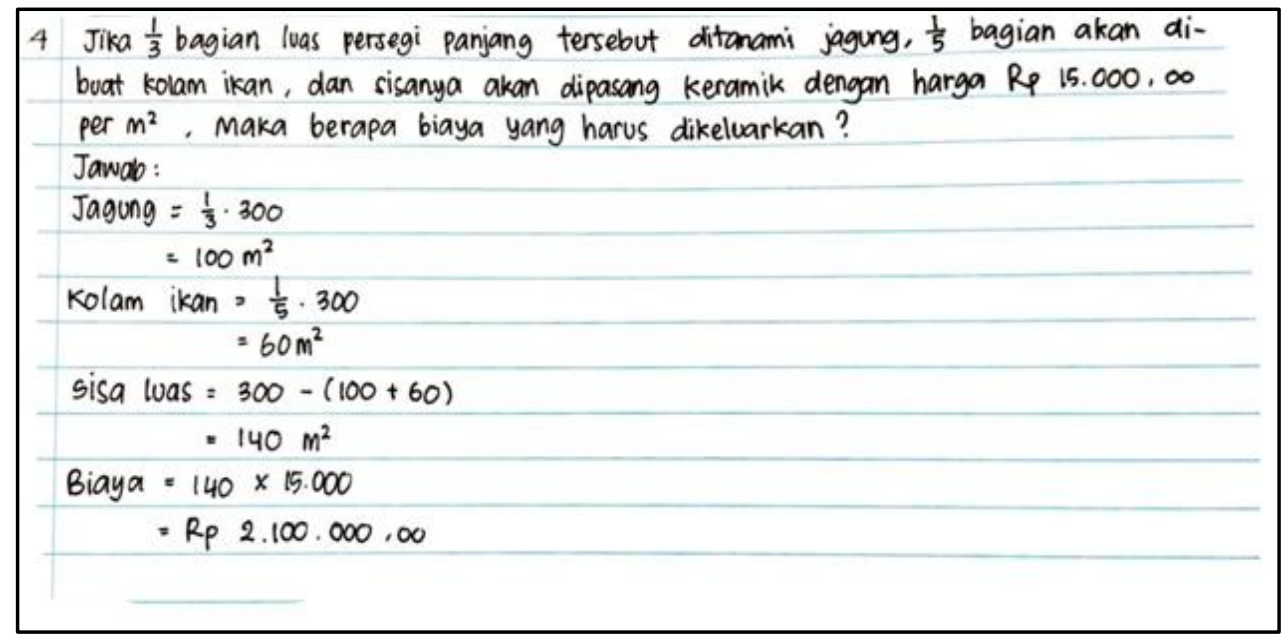

\section{Figure 5. The problem with 4-relationship}

Based on Figure 5, the problems posed by students can be categorized as restating, grouping, comparing and varying. In this problem, the student used existing data in the form of the length and width of the original and then group it into new areas for the corn 
garden, fish ponds, and the remaining area to be installed tiles. Indirectly, students have varied and compared problems from the information that has been given. This can be seen from the answer, namely, students must use multiplication operations to obtain the costs required for tile installation.

Furthermore, the problems that can be categorized would be analyzed based on language structure (syntax). The results of the syntactic analysis are as follows.

Table 3. Results of Analysis Based on Syntax

\begin{tabular}{cccc}
\hline The Number of & \multicolumn{3}{c}{ Syntactic } \\
\cline { 2 - 4 } Problems & P. Assgn & P. Con & P. Sup \\
\hline 54 & 23 & 17 & 14 \\
$\%$ & 42,59 & 31,48 & 25,93 \\
\hline
\end{tabular}

Note:

P. Assgn : Proportion of Assignment

P. Con : Proportion of Connection

P. Sup : Proportion of Supposition

Table 3 showed that based on the syntax analysis, more than forty percent of students were able to pose problems using assignment propositions. Furthermore, more than onethird of students, able to pose problems using the proposition of relations. While more than quarter students pose a problem using the supposition proposition. It showed the relationship process are needed to build relationships with mathematics (Dominguez, Lópezleiva, \& Khisty, 2013) in problem-posing. This can develop well if there are significant interactions between teacher's perceptions and knowledge (Campbell et al., 2014) that affect students' ability's problem-posing.

The student posed problem using assignment proposition

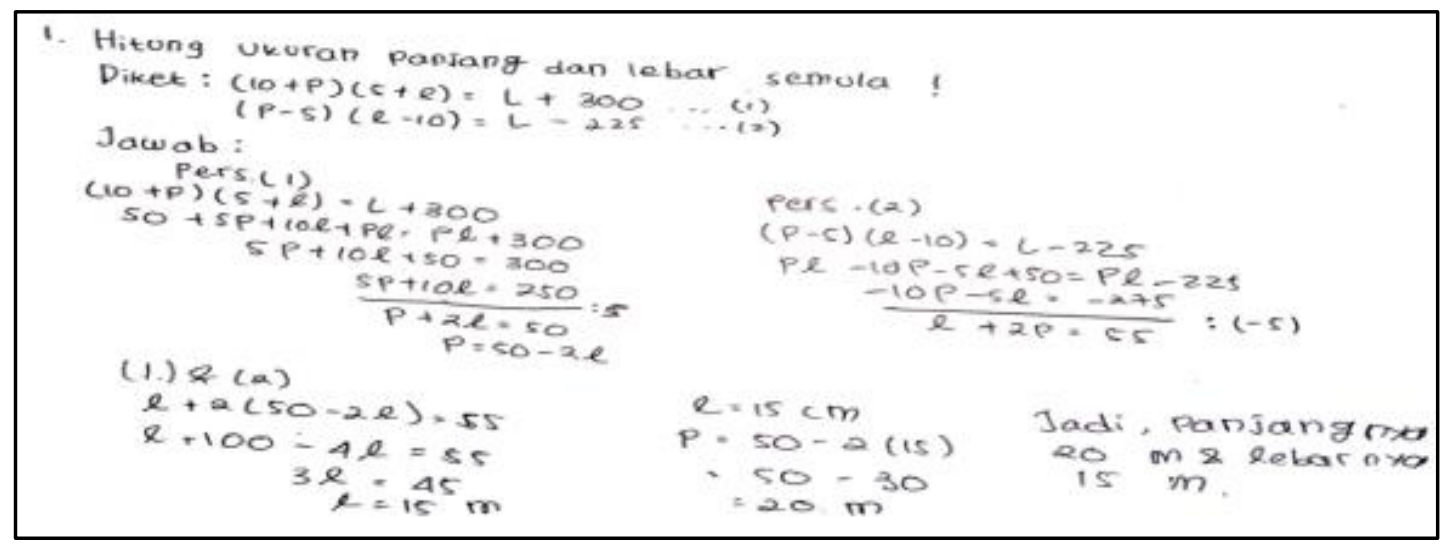

Figure 6. The problem using assignment proposition

Based on Figure 5, the problems posed by students contains the task to calculate the length and width based on the information that has been given. Thus, the problem can be categorized using assignment proposition.

\section{The student posed problem using preposition of relationship}

Figure 7 showed that the problems posed by students belonging to the category of a relational proposition. This problem contains the task of comparing where students compare the area if the size of the length and width is replaced from the original size. 


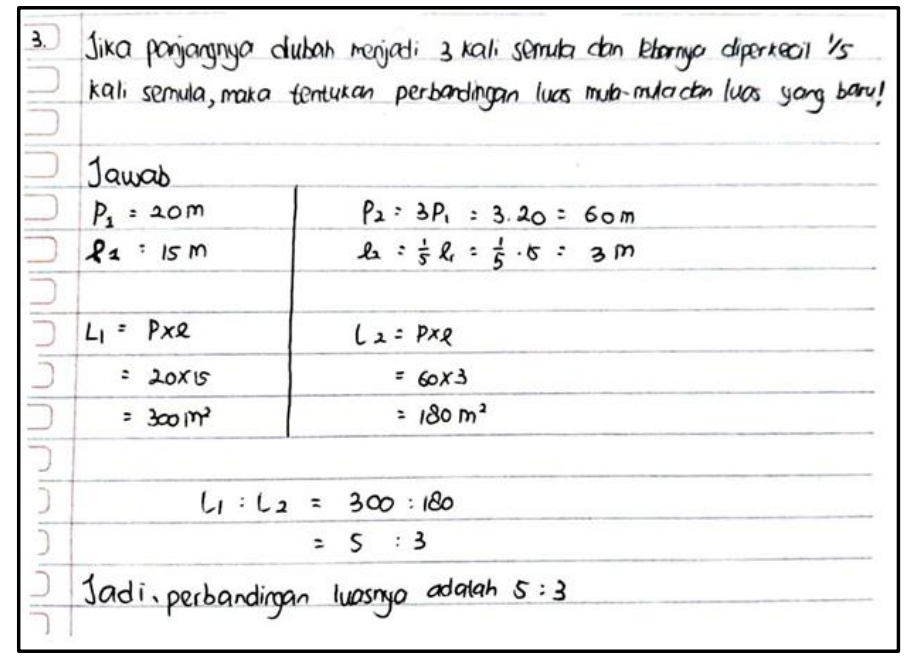

Figure 7. The problem using relationship proposition

The student posed problem using a supposition proposition

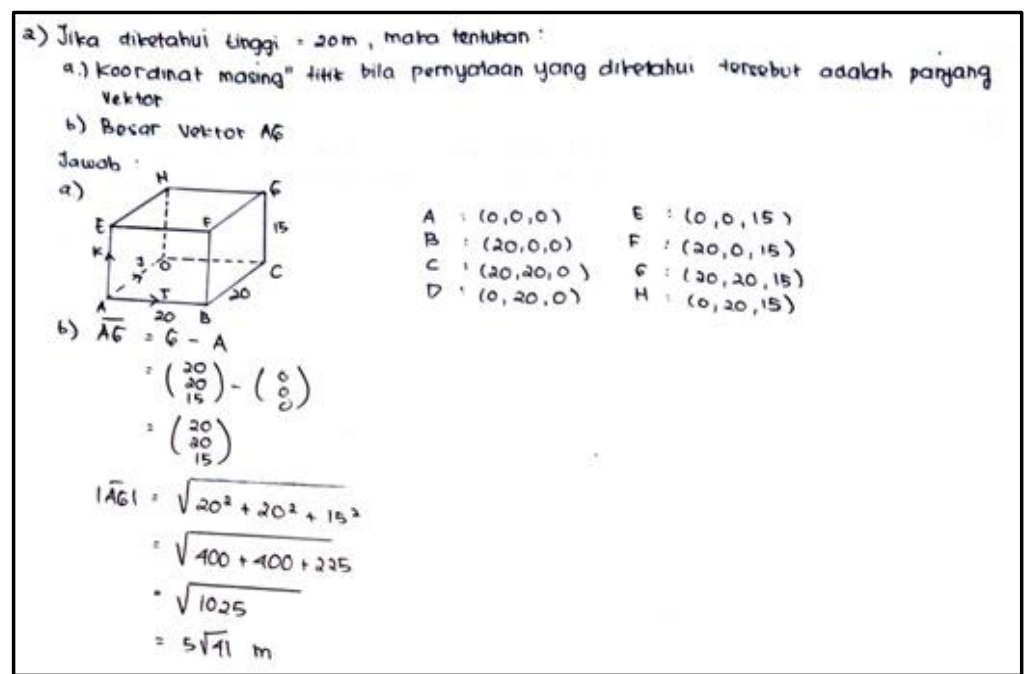

Figure 8. The problem using a supposition proposition

Based on Figure 8, the problems posed by students are included in the conditional proposition category. This problem contains additional information where students are able to connect mathematical concepts. In this case, students connect existing information with other mathematical material namely, vector concepts.

\section{Conclusion}

Based on the results of research and discussion that has been conducted on 60 middle school students in the East Surabaya area in submitting the SLETV problem, it can be concluded that students are able to submit problems can be categorized. Data obtained that students find it easier to posed SLETV problems involving just one relationship besides other relationships. Whereas, based on language structure (syntax), most students are able to pose problems using the proposition of relationships than others. We suggest that the teachers should promote the students with the knowledge to be able to pose complex problems related in daily life situation. Furthermore, there needs research about problems posing in other mathematics subjects. 


\section{References}

Berch, D. B., \& Mazzocco, M. M. M. (2007). Why is math so hard for some children? The Nature and Origins of Mathematical Learning Difficulties and Disabilities (Paul H. Br). Maryland.

Brown, S. I., \& Walter, M. I. (1990). The Art of Problem Posing (Second Edi). New Jersey: Lawrence Erlbaum Associates Publishers.

Cai, J., Hwang, S., Jiang, C., \& Silber, S. (2015). Problem-Posing Research in Mathematics Education: Some Answered and Unanswered Question. In Mathematical Problem Posing From Research to Effective Practice (pp. 3-29). New York: Springer.

Campbell, P. F., Nishio, M., Smith, T. M., Clark, L. M., Darcy, L., Rust, A. H., ... Griffin, M. J. (2014). The Relationship Between Teachers ' Mathematical Content and Pedagogical Knowledge, Teachers ' Perceptions, and Student Achievement. Journal for Research in Mathematics Education, 45(4), 419-459.

Dominguez, H., Lópezleiva, C. A., \& Khisty, L. L. (2013). Relational engagement: Proportional reasoning with bilingual Latino / a students. Educ Stud Math, 85(1), 143-160. https://doi.org/10.1007/s10649-013-9501-7

Dwianto, D. A., \& Siswono, T. Y. E. (2016). Profil Komplekitas Soal yang Dibuat Siswa Dalam Pengajuan Masalah. Jurnal Ilmiah Pendidikan Matematika, 3(5), 83-91.

Gardiner, A. D., \& Borovik, A. (2007). Mathematical Abilities and Mathematical Skills. Manchester: The University Of Manchester.

Pape, S. J. (2004). Middle School Children's Problem-Solving Behavior: A Cognitive Analysis from a Reading Comprehension Perspective. Journal for Research in Mathematics Education, 35(3), 187-219.

Silver, E. A \& Cai, J. (1996). An Analysis of Arithmetic Problem Posing by Middle School Students. National Council of Teachers of Mathematics, 27(5), 521-539. Retrieved from http://www.jstor.org/stable/749846

Tuğrul, K. (2010). The Relation Between Problem Posing and Problem Solving Skills of Prospective Elementary Mathematics Teachers. Procedia-Social and Behavioral Sciences, 27(5), 521-539. 